\title{
Dynamic Routing Model with Real-Time Roughness Updating for Flood Forecasting
}

\author{
Ming-Hsi Hsu'; Jin-Cheng $\mathrm{Fu}^{2}$; and Wen-Cheng $\mathrm{Liu}^{3}$
}

\begin{abstract}
A flood routing model with time-varying roughness updating was developed to simulate flows through natural channels based on the dynamic wave theory. Taking observed stages as the targets, a roughness updating technique was developed using the GaussNewton method to update the Manning $n$ in each time step of the routing processes. The technique provides a reasonable roughness coefficient estimate and reliable initialization of stage profile for the forecast. The examinations including the initialization of stage profile, conservation of mass, iteration convergence, effectiveness evaluation, and convergence with different initial values were conducted to verify the predictive capability of the roughness updating technique. The forecasting results show that the stage recalculated by updating the Manning $n$ in current time has a good agreement with the observed stage. The presented model can improve the forecast for a lead time up to $6 \mathrm{~h}$ in the Tanshui River of northern Taiwan.
\end{abstract}

DOI: 10.1061/(ASCE)0733-9429(2006)132:6(605)

CE Database subject headings: Floods; Forecasting; Roughness; Rivers; Taiwan; Routing.

\section{Introduction}

Flash floods usually result in disasters, which inflict heavy losses of life and property. With the greatly improved speed and capacity of digital computers in recent years, dynamic routing models have been widely used for flood forecasting (Nguyen and Kawano 1995; Lamberti and Pilati 1996; Saavedra et al. 2003). However, real time observed data are seldom incorporated into the dynamic routing models to improve the forecasting accuracy. To remedy this deficiency, Shiiba et al. (2000) developed a stochasticdynamic flood routing model based on the Kalman filtering theory to improve the forecast in conjunction with water stage or discharge observation. Hsu et al. (2003) used the least-square method combined with the dynamic wave routing model to solve the overdetermined equations that include the extra internal boundary conditions specified by the real time observed stages. Although the method offers a reliable initialization of stage profile for flood forecast, the Manning $n$ was fixed through a whole time series of events. The forecasting results from the stochasticdynamic routing or the least-square method of dynamic routing provides more accurate forecast, but their improvement gradually diminished when one predicts far ahead in time due to a lack of parameter updating.

A proper technique for the parameter estimate in response to

${ }^{1}$ Professor, Dept. of Bioenvironmental Systems Engineering, National Taiwan Univ., Taipei 10617, Taiwan (corresponding author). E-mail: mhhsu@ntu.edu.tw

${ }^{2}$ Assistant Researcher, National Science and Technology Center for Disaster Reduction, Taipei 10617, Taiwan.

${ }^{3}$ Associate Professor, Dept. of Civil and Disaster Prevention Engineering, National United Univ., Miao-Li 36003, Taiwan.

Note. Discussion open until November 1, 2006. Separate discussions must be submitted for individual papers. To extend the closing date by one month, a written request must be filed with the ASCE Managing Editor. The manuscript for this paper was submitted for review and possible publication on June 15, 2004; approved on July 8, 2005. This paper is part of the Journal of Hydraulic Engineering, Vol. 132, No. 6, June 1, 2006. ()ASCE, ISSN 0733-9429/2006/6-605-619/\$25.00. the flow conditions in a river is an interesting work for hydraulic engineers. Several researchers have made attempts to study the parameters affected by the flows in their research works. Kachroo (1992) presented a comprehensive discussion on an operational mathematical model for river flow forecasting and indicated that the parameters in the forecasting model had physical interpretation, and their values might be established by field investigation. The forecasting accuracy can be improved by linking with the objective function used for optimizing parameters of the model. Ackers (1992) showed that the calculated value of the Manning $n$ varied with the stage according to the field observation in rivers and recommended that channel resistance be expressed through appropriate adjustment factors. Alain (1992) provided an iterative method for estimating the values of the Manning roughness coefficient for open channel flow. Randy et al. (1993) coupled the Kalman filtering to estimate the Manning $n$ in flow modeling and forecasting for the Niagara River. Liggett and Chen (1994) used the optimal method to adjust parameters so as to minimize the difference between calculated and measured heads in pipe network. Camacho and Lees (1999) used time-variable parameters which are related to physical channel characteristics in a multilinear discrete lag-cascade model for channel routing. Khatibi et al. (2000) showed that the value of Manning $n$ may vary with stage, vegetation, siltation, scour, and flow conditions at any point in space and time. Dey (2002) expressed the Manning $n$ as a function of channel bottom slope for both the subcritical and supercritical flows. Liu et al. (2003) computed the Manning $n$ with two sets of empirical equations depending on water depth and vegetation to investigate the effects of mangrove trees on flow resistance in a tidal river. Romanowicz and Beven (2003) provided the conveyance parameters which were conditioned on maximum inundation extent observation as a constraint on uncertainty in the prediction of flood risk. If the observed stage data along the river are available, it is possible by the optimization method to determine a better parameter so that the computed water levels match the observed stages. In this study, the Manning $n$ is updated to minimize the differences between observed and forecasting river stages during the routing process. 
Because of the steep terrain, tropical cyclone storms often result in disastrous flash floods in rivers in Taiwan, with a very short time delay following the storm. A flood forecasting model can be used to provide adequate warning in advance for floodmitigation. The objective of this paper is to present a roughness updating technique combined with a one-dimensional flood routing model for flood forecasting. During the roughness updating process, the real time observed stage was used as a target for the optimization.

\section{Model Development and Methodology}

The dynamic routing model is based on the dynamic wave theory of the Saint-Venant equations which consist of the continuity and momentum equations

$$
\begin{gathered}
\frac{\partial A}{\partial t}+\frac{\partial Q}{\partial x}-q_{1}+q_{2}=0 \\
\frac{\partial Q}{\partial t}+\frac{\partial}{\partial x}\left(\frac{Q^{2}}{A}\right)-g A\left(S_{0}-\frac{\partial Y}{\partial x}-S_{f}\right)-q_{1} V_{1}+q_{2}\left(\frac{Q}{A}\right)=0
\end{gathered}
$$

where $A=$ cross-sectional area; $Y=$ water depth; $Q=$ discharge; $q_{1}=$ lateral inflow per unit channel length; $q_{2}=$ lateral outgoing overflow per unit channel length; $S_{0}=$ channel bottom slope; $S_{f}=$ friction slope; $V_{1}=$ longitudinal velocity component of lateral inflow; $g=$ gravitational acceleration; $t=$ time; and $x=$ distance along the channel. Since the cross-sectional area can be expressed as a function of water depth, only two flow variables, $Q$ and $Y$, need to be solved in Eqs. (1) and (2).

The numerical solution of Eqs. (1) and (2) can be obtained if appropriate initial and boundary conditions are prescribed. In this work, the four-point implicit finite-difference approximation (Preissman 1961; Amein and Fang 1970) is used to solve the equations. In the process of discretization, the two adjoining cross sections can be organized into two equations with four unknowns of flow variables at the advanced time

$$
\begin{aligned}
& C_{\ell}\left(Q_{\ell+1}^{t+1}, Y_{\ell+1}^{t+1}, Q_{\ell}^{t+1}, Y_{\ell}^{t+1}, Q_{\ell+1}^{t}, Y_{\ell+1}^{t}, Q_{\ell}^{t}, Y_{\ell}^{t}\right)=0 \\
& M_{\ell}\left(Q_{\ell+1}^{t+1}, Y_{\ell+1}^{t+1}, Q_{\ell}^{t+1}, Y_{\ell}^{t+1}, Q_{\ell+1}^{t}, Y_{\ell+1}^{t}, Q_{\ell}^{t}, Y_{\ell}^{t}\right)=0
\end{aligned}
$$

where $C_{\ell}$ and $M_{\ell}$ represent the discretized continuity and momentum equations between the $\ell$ th and the $(\ell+1)$ th cross sections, respectively. The subscript $\ell$ is the cross-sectional index, for $1,2, \ldots, L$, numbering from upstream to downstream, $t$ and $(t+1)$ the flow variables at the present and advanced times, respectively.

For a river with $L$ cross sections, a system of $(2 L-2)$ equations with $2 L$ unknowns of flow variables will result. The deficiency in the number of equations is supplemented with boundary conditions in order to solve for the unknowns of flow variables at the next time step. The boundary conditions of the dynamic routing model are the discharges at the upstream watershed and the tide stages at the river mouth. The meteorological typhoon quantitative precipitation forecast model supplies the rainfall for the runoff forecasting model to produce the discharges (Lee et al. 2000; Wang and Hsieh 2000). The tide stages are the summation of the astronomical tide from the harmonic analysis and the meteorological tide, which is the difference between the observed and the astronomical tidal stages (Hsu et al. 2000). The iterative Newton method is then used to solve the nonlinear equations.

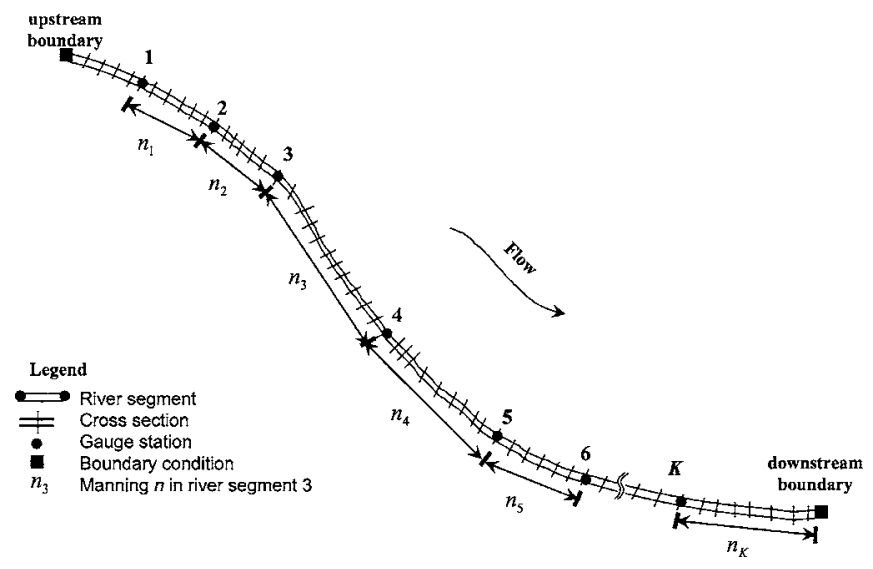

Fig. 1. Schematic representation of river segments and gauge stations

The friction slope $\left(S_{f}\right)$ in the momentum equation accounts for the resistance of flow. The friction slope is related to the roughness coefficient and flow variables from Manning formula

$$
S_{f}=\frac{n^{2} Q|Q|}{R^{4 / 3} A^{2}}
$$

where $R=$ hydraulic radius and $n=$ Manning roughness coefficient.

The Manning $n$ in Eqs. (3) and (4) is usually calibrated by a simulation of previous flood events, and the value not further updated. Along with the advances in transmission technology, real time observed flood stages obtained from the gauge stations provides new flow information to get an optimal estimate of the Manning $n$. The discrete forms of continuity and momentum equations for the present and previous times are

$$
\begin{gathered}
C_{\ell}\left(Q_{\ell+1}^{t}, Y_{\ell+1}^{t}, Q_{\ell}^{t}, Y_{\ell}^{t}, Q_{\ell+1}^{t-1}, Y_{\ell+1}^{t-1}, Q_{\ell}^{t-1}, Y_{\ell}^{t-1}\right)=0 \\
M_{\ell}\left(Q_{\ell+1}^{t}, Y_{\ell+1}^{t}, Q_{\ell}^{t}, Y_{\ell}^{t}, Q_{\ell+1}^{t-1}, Y_{\ell+1}^{t-1}, Q_{\ell}^{t-1}, Y_{\ell}^{t-1}\right)=0
\end{gathered}
$$

Suppose that interior gauge stations are numbered $1,2,3, \ldots, K$ from upstream to downstream in a river. The river can be divided into $K$ river segments according to the gauge stations. A segment consists of a number of cross sections with the boundaries at the gauge stations or downstream boundary of the model. The first river segment is located between the first and second gauge stations. The last river segment is situated between the $K$ th gauge station and the downstream boundary (shown in Fig. 1). The study assumes that the cross sections in a river segment have the same $n$ values, so that each segment gives a Manning $n$ and there are $K$ segments used for $n$ updating in a river.

During the flood period, there are $K$ gauge stations at which water depths are observed in a river. The real time observed water depths are considered as the targets for the computation at the present time. Therefore, the goal is to update the Manning $n$ (denoted by $\Omega$ ) of river segments for the dynamic routing model, so that the numerically computed water depths at the gauge stations, denoted by $Y_{k}$, are as close as possible to the targets $\bar{Y}_{k}$ at the present time. The updating $n$-values technique can offer the optimal roughness at the present time for the flood forecasting. The roughness updating technique is formulated as a nonlinear, least-square minimization problem with respect to the objective function as follows: 


$$
\min _{\Omega} f(\Omega)=\frac{1}{2} \sum_{k=1}^{K}\left(Y_{k}-\bar{Y}_{k}\right)^{2}
$$

where $f$ =objective function; and $\Omega=$ updating vector of $n$ values in those identifying river segments. The $Y_{k}$ and $\bar{Y}_{k}$ are the present time computed and the observed water depths at the $k$ th gauge station, respectively.

In this study, the Gauss-Newton method is used to solve the nonlinear least-square problem. According to the Gauss-Newton method, we can determine the updating $n$ values $[\Omega]_{m+1}$ from $[\Omega]_{m}$ by using the following expression (Jorge and Stephen 1999):

$$
[\Omega]_{m+1}=[\Omega]_{m}+[\Delta \Omega]_{m}
$$

and

$$
[\Delta \Omega]_{m}=-\left[[\Phi]_{m}^{T} \cdot[\Phi]_{m}\right]^{-1} \cdot\left[[\Phi]_{m}^{T} \cdot[\mathrm{E}]_{m}\right]
$$

where the subscript $m=$ iteration number and superscript $T=$ matrix transposes. $[\Omega]_{m}=\left[n_{1}, n_{2}, n_{3}, \ldots, n_{K}\right]_{m}^{T}$ represents $n$-values matrix of river segments, $[\Delta \Omega]_{m}=\left[\Delta n_{1}, \Delta n_{2}, \Delta n_{3}, \ldots, \Delta n_{K}\right]_{m}^{T}=$ current increment of $n$ values, and $[\mathrm{E}]_{m}=$ the difference between the computed and observed water depths

$$
[\Phi]_{m}=\left[\frac{\partial Y}{\partial n}\right]_{i, j}=\left[\begin{array}{c}
Y_{1}-\bar{Y}_{1} \\
Y_{2}-\bar{Y}_{2} \\
Y_{3}-\bar{Y}_{3} \\
\vdots \\
Y_{K}-\bar{Y}_{K}
\end{array}\right]_{m}=\left[\begin{array}{ccccc}
\frac{\partial Y_{1}}{\partial n_{1}} & \frac{\partial Y_{1}}{\partial n_{2}} & \frac{\partial Y_{1}}{\partial n_{3}} & \ldots & \frac{\partial Y_{1}}{\partial n_{K}} \\
\frac{\partial Y_{2}}{\partial n_{1}} & \frac{\partial Y_{2}}{\partial n_{2}} & \frac{\partial Y_{2}}{\partial n_{3}} & \ldots & \frac{\partial Y_{2}}{\partial n_{K}} \\
\frac{\partial Y_{3}}{\partial n_{2}} & \frac{\partial Y_{3}}{\partial n_{3}} & \ldots & \frac{\partial Y_{3}}{\partial n_{K}} \\
\vdots & \vdots & \vdots & \ddots & \vdots \\
\frac{\partial Y_{K}}{\partial n_{1}} & \frac{\partial Y_{K}}{\partial n_{2}} & \frac{\partial Y_{K}}{\partial n_{3}} & \ldots & \frac{\partial Y_{K}}{\partial n_{K}}
\end{array}\right]_{m}
$$

The subscript $i$ and $j$ of the matrix $[\Phi]_{m}$ in Eq. (12) are the indices of gauge station and $n$-updating river segment, respectively, for $1,2, \ldots, K$, numbering from upstream to downstream. The final $n$ values $[\Omega]_{m+1}$ can be found through iteration until the absolute value of current increment of Manning $n\left([\Delta \Omega]_{m}\right)$ is smaller than the tolerance $\left(1 \times 10^{-4}\right)$. In the updating processes, the water depths at the gauge stations $\left(Y_{k}\right)$ are calculated by Eqs. (6) and (7) where the newly updated $n$ values are used.

The Jacobian of the residuals $[\Phi]_{m}$ expressing the derivative of water depth in terms of the full momentum equation [Eq. (2)] is complicated. Because the acceleration terms and the momentum flux of lateral flows are always small to compare with other terms in Eq. (2), including bed slope $\left(S_{0}\right)$, friction term $\left(S_{f}\right)$, and pressure gradient for flood routing in a river (Henderson 1966), the steady gradually varied flow is assumed and used in the processing of $n$-updating iteration. Thus, the elements $[\partial Y / \partial n]_{i, j}$ in Eq. (12) are expanded by the nonuniform flow equation. With the consideration of relative locations between the gauge station $(i)$ and $n$-updating river segment $(j)$, the elements of $[\Phi]_{m}$ in Eq. (12) give three possible cases.

(1) $i=j$. The elements lie along the diagonal of $[\Phi]_{m}$, which means that the river segment with the modified Manning $n$ has a significant effect on the water depth when the gauge station is located at the $n$-updating river segment. In the processing of $n$-updating iterations, we assume that the flood flow is steady and the channel is wide and shallow, thus the hydraulic radius $(R)$ is approximately equal to the water depth $(Y)$. Then, the water depth at a gauge station can be expressed by the Manning formula

$$
Y=\left(\frac{Q n}{B S_{f}^{1 / 2}}\right)^{3 / 5}
$$

where $Q, B$, and $S_{f}$ represent the discharge, surface width, and friction slope of a gauge station, respectively. We further assume that the three variables do not vary with water depth in the processes of $n$-updating iterations.

Thus the derivative of Eq. (13) with respect to the Manning $n$ is

$$
\left[\frac{\partial Y}{\partial n}\right]_{i, j}=\left[\frac{\partial}{\partial n}\left(\frac{Q n}{B S_{f}^{1 / 2}}\right)^{3 / 5}\right]_{i, j}=\frac{3 Y_{i}}{5 n_{j}}
$$

(2) $i<j$. When gauge stations are located at the upstream sites of $n$-updating river segment, the influence of water depth, caused by the downstream $n$-updating river segment, can be accounted for by the nonuniform flow equation. With the consideration of the backwater effects, the upper triangular elements of $[\Phi]_{m}$ can be derived from the equation of gradually varied flows as

$$
\left[\frac{\partial Y}{\partial n}\right]_{i, j}=\frac{3 Y_{j}}{5 n_{j}} \prod_{\lambda=i}^{j-1} D_{\lambda}
$$

where

$$
\prod_{\lambda=i}^{j-1} D_{\lambda}=D_{i} D_{i+1} D_{i+2} \cdots D_{j-1}, \quad D_{\lambda}=\left(\frac{1-\frac{\partial \psi_{\lambda}}{\partial Y_{\lambda+1}}}{1+\frac{\partial \psi_{\lambda}}{\partial Y_{\lambda}}}\right)
$$

is the coefficient of the backwater effects between two adjoining gauge stations

$$
\psi_{i}=\left(\frac{S_{0}-\frac{1}{2}\left(S_{f i}+S_{f_{i+1}}\right)}{1-\frac{1}{2}\left(F_{i}^{2}+F_{i+1}^{2}\right)} \Delta X_{i}\right)
$$

The coefficients can be expressed as a function of the derivatives of the difference in water depth between the two adjoining gauge stations with respect to each of the water depths. The expression of $D_{\lambda}$ and the detailed derivation of Eq. (15) are shown in the Appendix.

(3) $i>j$. When the gauge station is located at the downstream site of $n$-updating river segment, the lower triangular elements of $[\Phi]_{m}$ are set to zero under the assumption that the influence of water depth at the downstream gauge station caused by the varying Manning $n$ in the upstream segment is negligible. Therefore, the lower triangular elements are

$$
\left[\frac{\partial Y}{\partial n}\right]_{i, j}=0
$$




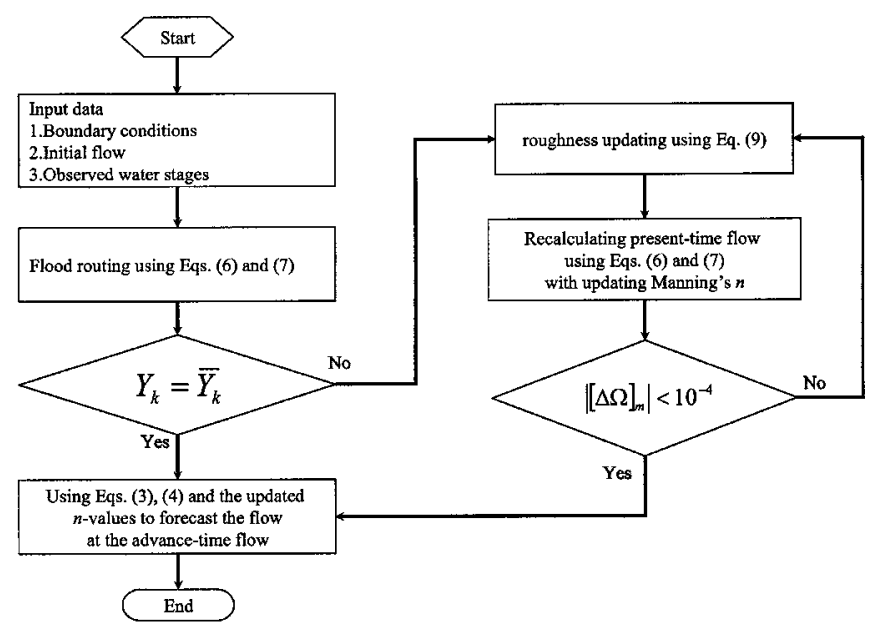

Fig. 2. The procedures of roughness updating technique stream $n$ updating in the main stream can affect the water depths in upper tributaries. Thus, the coefficient $D_{\lambda}$ is used to represent the backwater effects in the main stream as well as tributaries.

The errors of water depth at the gauge stations gradually diminish to meet the objective function through the iteration processes of the $n$ value updating. The procedures of roughness updating technique are depicted in Fig. 2. The figure shows that if the computed stage does not meet the measured stage at gauge stations at the present time, the roughness updating technique is used to find the new Manning $n$ until the desired convergence criteria are attained. Following this the computation of dynamic routing in the advanced time can be proceeded by solving Eqs. (3) and (4) with the newly updated $n$ values. Since the Manning $n$ is a function of computed stage in the routing model, a reliable initialization of water stage at the present time is obtained simultaneous with the $n$ updating. The new Manning $n$ is then used to forecast the advance time flows in the dynamic routing model.

\section{Description of Study Site}

The elements of $[\Phi]_{m}$ in Eq. (12), derived from Eqs. (14)-(16), can be summarized as

$$
\left[\frac{\partial Y}{\partial n}\right]_{i, j}= \begin{cases}\frac{5 Y_{i}}{3 n_{j}} & \text { if } i=j \\ \frac{5 Y_{j}}{3 n_{j}} \prod_{\lambda=i}^{j-1} D_{\lambda} & \text { if } i<j \\ 0 & \text { if } i>j\end{cases}
$$

For the river system with tributaries, we assume that the $n$ updating in a tributary has no effect on the water depth of river segments in the main stream and other tributaries. The down-
The Tanshui River basin (Fig. 3), located in northern Taiwan, consists of three major tributaries: Tahan Creek, Hsintien Creek, and Keelung River. They are confluent in the lowest part of the basin to form the Tanshui River. Within the lowland area, there is the metropolitan city of Taipei with a population of approximately six million and a great deal of economic and cultural activities. The drainage area of the river basin is $2,726 \mathrm{~km}^{2}$ with a mean annual precipitation of $3,001 \mathrm{~mm}$. The total channel length is $327.6 \mathrm{~km}$ and the channel slope ranges from 0.015 to $2.7 \%$. The steep land slopes and short river courses make the time of floodwater convergence very short, approximately 3-6 h. Flood inundation in the lowland of the metropolitan Taipei often occurs and causes heavy losses when typhoons or rainstorms strike. The Central Weather Bureau has reported that the mean annual loss due to

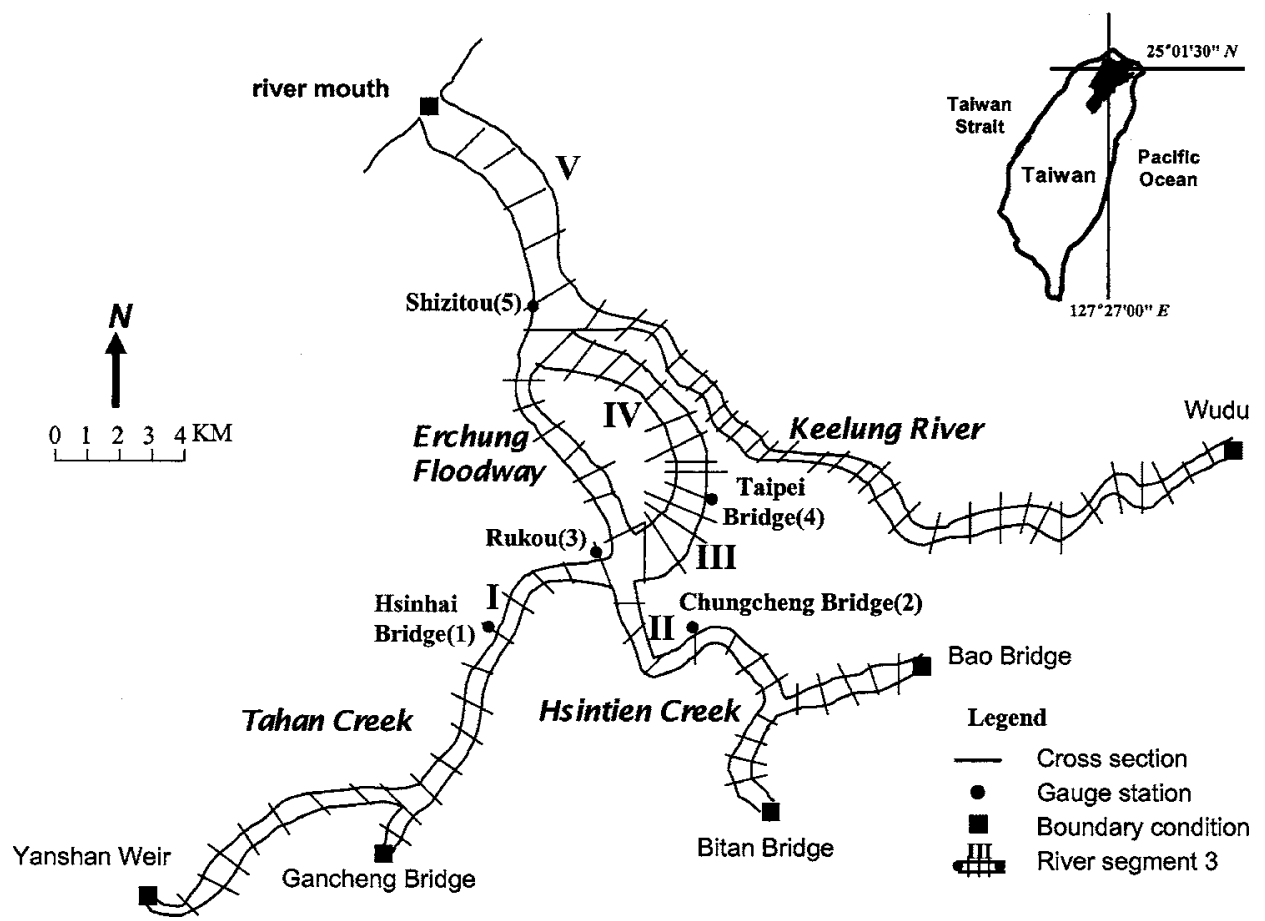

Fig. 3. Layout of the Tanshui River system 


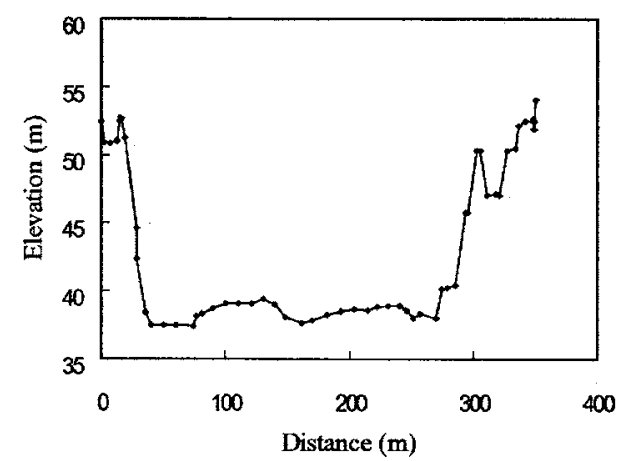

(a) Yanshan Weir (Tahan Creek)

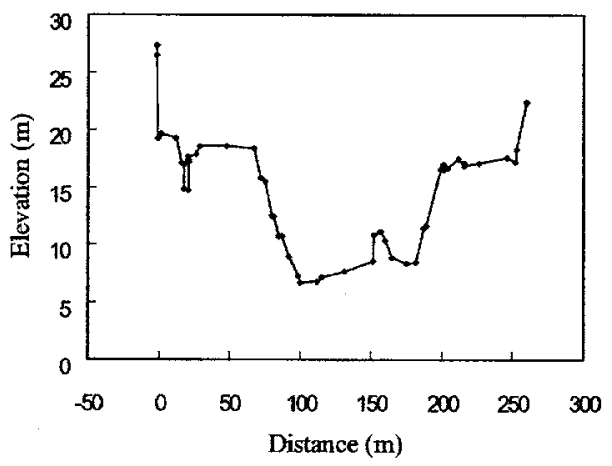

(b) Gancheng Bridge (Sanxia Creek)

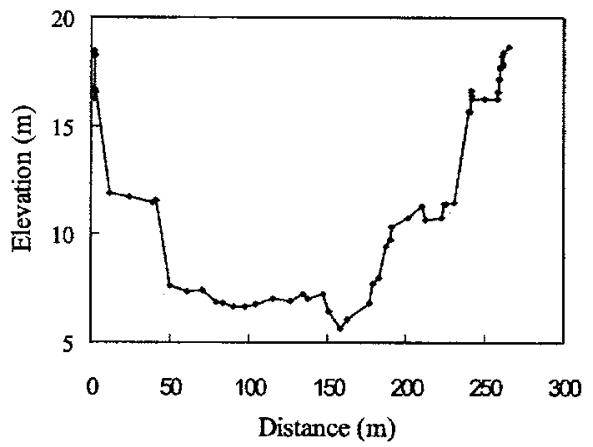

(c) Bitan Bridge (Hsintien Creek)

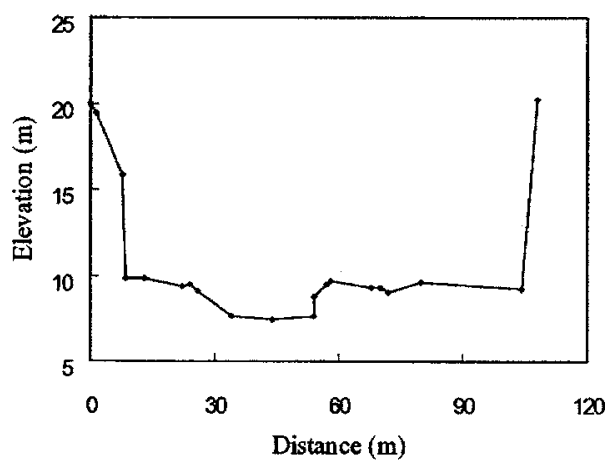

(d) Bao Bridge (Jingmei Creek)

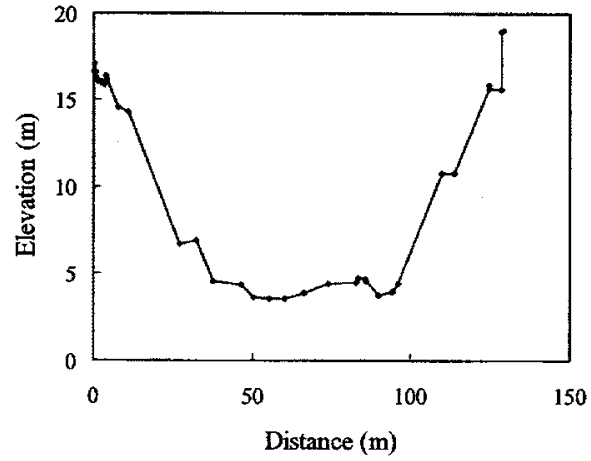

(e) Wudu (Keelung River)

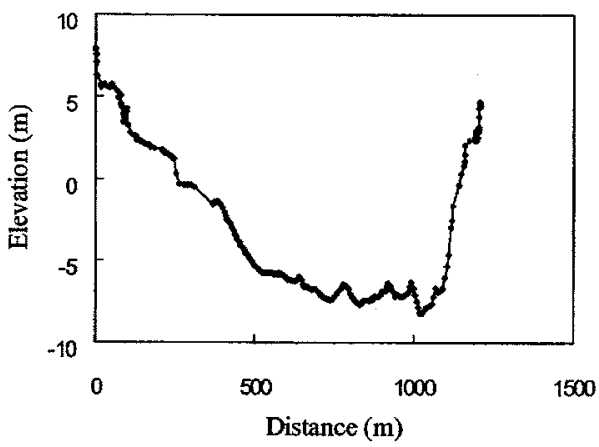

(f) River mouth (Tanshui River)

Fig. 4. The typical cross section of the Tanshui River

Table 1. Roughness Values Calibrated by the Nine Typhoon Events

\begin{tabular}{|c|c|c|c|c|c|c|c|c|c|c|}
\hline \multirow[b]{2}{*}{ River segment } & \multicolumn{10}{|c|}{ Manning $n$} \\
\hline & $\begin{array}{c}\text { Typhoon } \\
\text { Elsie }\end{array}$ & $\begin{array}{c}\text { Typhoon } \\
\text { Bess }\end{array}$ & $\begin{array}{c}\text { Typhoon } \\
\text { Betty }\end{array}$ & $\begin{array}{c}\text { Typhoon } \\
\text { Billie }\end{array}$ & $\begin{array}{c}\text { Typhoon } \\
\text { Vera }\end{array}$ & $\begin{array}{c}\text { Typhoon } \\
\text { Ora }\end{array}$ & $\begin{array}{c}\text { Typhoon } \\
\text { Nelson }\end{array}$ & $\begin{array}{c}\text { Typhoon } \\
\text { Polly }\end{array}$ & $\begin{array}{c}\text { Typhoon } \\
\text { Ted }\end{array}$ & Calibrated \\
\hline Hsinhai Bridge-Rukou & 0.033 & 0.033 & 0.030 & 0.033 & 0.030 & 0.033 & 0.033 & 0.033 & 0.033 & 0.033 \\
\hline Chungcheng Bridge-Rukou & 0.033 & 0.027 & 0.027 & 0.027 & 0.030 & 0.027 & 0.033 & 0.030 & 0.033 & 0.032 \\
\hline Rukou-Taipei Bridge & 0.030 & 0.028 & 0.025 & 0.030 & 0.032 & 0.030 & 0.030 & 0.030 & 0.030 & 0.030 \\
\hline Taipei Bridge-Shizitou & 0.023 & 0.020 & 0.025 & 0.030 & 0.025 & 0.020 & 0.020 & 0.030 & 0.020 & 0.023 \\
\hline Shizitou-river mouth & 0.020 & 0.024 & 0.022 & 0.024 & 0.020 & 0.024 & 0.018 & 0.024 & 0.022 & 0.023 \\
\hline
\end{tabular}


flood events in Taiwan is about US\$500 million (Yen et al. 1998). In order to reduce the loss of life and property caused by flood, the Taipei Flood Mitigation Project was initiated in 1982, and completed in 1997. The project was designed for protection against the 200 year flood. The major components include: Levees, a diversion channel (the Erchung Floodway, Fig. 3), pumping stations, flood control gates, drainage systems, and channel improvement. In addition, the Water Resources Agency of the Ministry of Economic Affairs established the Tanshui River Flood Forecasting System to mitigate flood damage in 1977. Real time flood forecasting system was completed in December 1998 (Yen et al. 1998). In these projects, fixed values of the Manning roughness were used in the model to predict the flood stage.

In this study, the model transects are established with the measured cross-sectional profiles at about $0.5 \mathrm{~km}$ interval along the river. Fig. 3 shows the model transects in the computational domain that includes 210 transects. The typical cross sections of the Tanshui River are presented in Fig. 4. Because the channel shapes are wide and shallow, the effects of two-stage channels (main channel and floodplains) (Ackers 1992) are not obvious in the Tanshui River. Therefore the same Manning $n$ for the main channel and floodplain is used in the study. The upstream boundaries are specified at the Yanshan Weir (Tahan Creek), Gancheng
Bridge (Sanxia Creek, a tributary of Tahan Creek), Bitan Bridge (Hsintien Creek), Bao Bridge (Jingmei Creek, a tributary of Hsintien Creek), and Wudu (Keelung River). The downstream boundary is at the river mouth. The measured water stages are transmitted every hour from the five gauge stations, Hsinhai Bridge, Chungcheng Bridge, Rukou, Taipei Bridge, and Shizitou, and then the measured stages are used to update the Manning $n$ of river segments each hour in the numerical model. Taking the gauge stations as the dividing points, the Tanshui River is divided into five $n$-updating river segments. They are the Hsinhai BridgeRukou (first segment), Chungcheng Bridge-Rukou (second segment), Rukou-Taipei Bridge (third segment), Taipei BridgeShizitou (fourth segment), and Shizitou-river mouth (fifth segment). The locations of these five gauge stations and river segments in the Tanshui River are presented in Fig. 3.

\section{Validation of Roughness Updating Technique}

Considering the layout and numbering of the gauge stations and river segments in the Tanshui River (shown in Fig. 3), the Jacobian of residuals $[\Phi]$ can be expanded by Eq. (17)

$$
[\Phi]_{5 \times 5}=\left[\begin{array}{ccc}
\frac{3 Y_{1}}{5 n_{1}} & \frac{3 Y_{2}}{5 n_{2}} D_{1} & \frac{3 Y_{3}}{5 n_{3}} D_{1} D_{2} \\
0 & \frac{3 Y_{2}}{5 n_{2}} & \frac{3 Y_{3}}{5 n_{3}} D_{2} \\
0 & 0 & \frac{3 Y_{3}}{5 n_{3}} \\
0 & 0 & 0 \\
0 & 0 & 0
\end{array}\right.
$$

where $Y_{1}, Y_{2}, Y_{3}, Y_{4}$, and $Y_{5}=$ computed water depth at the Hsinhai Bridge, Chungcheng Bridge, Rukou, Taipei Bridge, and Shizitou, respectively; $n_{1}, n_{2}, n_{3}, n_{4}$, and $n_{5}=$ Manning $n$ of the five river segments; and $D_{1}, D_{2}, D_{3}$, and $D_{4}=$ coefficients of backwater effects between two adjoining gauge stations.

In the Tanshui River system, the first and second river segments are regarded as the upstream tributaries. With the assumption that the $n$-updating in a tributary is irrelevant to the stages of other tributaries, the values of $\Phi_{1,2}\left[\left(3 Y_{2} / 5 n_{2}\right) D_{1}\right.$ in Eq. (18)] is set to zero. Further, because of the first segment adjoining the third segment (Fig. 3), the multiple coefficient of $D_{1} D_{2}$ appearing in the elements of $\Phi_{1,3}, \Phi_{1,4}$, and $\Phi_{1,5}$ of Eq. (18) are replaced by the $D_{1}^{\prime}=\left(\left(1-\partial \psi_{1} / \partial Y_{3}\right) /\left(1+\partial \psi_{1} / \partial Y_{1}\right)\right)$. In accordance with the special consideration of the tributaries in this case, the Eq. (18) can be rewritten as

$\left.\begin{array}{cc}\frac{3 Y_{4}}{5 n_{4}} D_{1} D_{2} D_{3} & \frac{3 Y_{5}}{5 n_{5}} D_{1} D_{2} D_{3} D_{4} \\ \frac{3 Y_{4}}{5 n_{4}} D_{2} D_{3} & \frac{3 Y_{5}}{5 n_{5}} D_{2} D_{3} D_{4} \\ \frac{3 Y_{4}}{5 n_{4}} D_{3} & \frac{3 Y_{5}}{5 n_{5}} D_{3} D_{4} \\ \frac{3 Y_{4}}{5 n_{4}} & \frac{3 Y_{5}}{5 n_{5}} D_{4} \\ 0 & \frac{3 Y_{5}}{5 n_{5}}\end{array}\right]$

$$
[\Phi]_{5 \times 5}=\left[\begin{array}{ccccc}
\frac{3 Y_{1}}{5 n_{1}} & 0 & \frac{3 Y_{3}}{5 n_{3}} D_{1}^{\prime} & \frac{3 Y_{4}}{5 n_{4}} D_{1}^{\prime} D_{3} & \frac{3 Y_{5}}{5 n_{5}} D_{1}^{\prime} D_{3} D_{4} \\
0 & \frac{3 Y_{2}}{5 n_{2}} & \frac{3 Y_{3}}{5 n_{3}} D_{2} & \frac{3 Y_{4}}{5 n_{4}} D_{2} D_{3} & \frac{3 Y_{5}}{5 n_{5}} D_{2} D_{3} D_{4} \\
0 & 0 & \frac{3 Y_{3}}{5 n_{3}} & \frac{3 Y_{4}}{5 n_{4}} D_{3} & \frac{3 Y_{5}}{5 n_{5}} D_{3} D_{4} \\
0 & 0 & 0 & \frac{3 Y_{4}}{5 n_{4}} & \frac{3 Y_{5}}{5 n_{5}} D_{4} \\
0 & 0 & 0 & 0 & \frac{3 Y_{5}}{5 n_{5}}
\end{array}\right]
$$

where $D_{1}^{\prime}, D_{2}, D_{3}$, and $D_{4}=$ coefficients of backwater effects of the Hsinhai Bridge-Rukou, Chungcheng Bridge-Rukou, RukouTaipei Bridge, and Taipei Bridge-Shizitou, respectively. 
Table 2. Effect of Different Time Steps on the Predicted Stage at the Taipei Bridge during the Xangsane Typhoon (at Peak Time $t=15 \mathrm{~h}$ )

\begin{tabular}{|c|c|c|c|c|c|c|}
\hline \multirow[b]{2}{*}{ Leading time } & \multicolumn{6}{|c|}{ Predicted stage $(\mathrm{m})$} \\
\hline & $\Delta t=60 \mathrm{~min}$ & $\Delta t=40 \mathrm{~min}$ & $\Delta t=30 \mathrm{~min}$ & $\Delta t=20 \mathrm{~min}$ & $\Delta t=15 \min$ & $\Delta t=10 \mathrm{~min}$ \\
\hline 1 & 3.72 & 3.76 & 3.75 & 3.76 & 3.76 & 3.77 \\
\hline 2 & 3.55 & 3.59 & 3.58 & 3.59 & 3.62 & 3.63 \\
\hline 3 & 3.32 & 3.33 & 3.33 & 3.33 & 3.35 & 3.35 \\
\hline 4 & 2.98 & 2.99 & 2.99 & 2.99 & 3.00 & 3.00 \\
\hline 5 & 2.55 & 2.55 & 2.56 & 2.55 & 2.56 & 2.56 \\
\hline 6 & 2.12 & 2.10 & 2.10 & 2.10 & 2.10 & 2.09 \\
\hline
\end{tabular}

The Manning roughness coefficient is the major parameter affecting the computed stages of dynamic routing model. A traditional trial-and-error method was usually used to calibrate the Manning $n$. In the Tanshui River system, the Manning roughness coefficients have been calibrated with nine typhoon events of Elsie (1969), Bess (1971), Betty (1972), Billie (1976), Vera (1977), Ora (1978), Nelson (1985), Polly (1992), and Ted (1992) by Yen et al. (1998). The roughness values calibrated with whole time series of the nine typhoon events are listed in Table 1 . The table shows that the roughness values are not consistent among the typhoon events. The average calibrated Manning $n$ was 0.033 , $0.032,0.030,0.023$, and 0.023 in the river segments of Hsinhai Bridge-Rukou, Chungcheng Bridge-Rukou, Rukou-Taipei Bridge, Taipei Bridge-Shizitou, and Shizitou-river mouth, respectively. In the study, the calibrated Manning coefficients are used as initial values for the roughness updating.

The study uses the Xangsane Typhoon (2000) to verify the roughness updating technique. The effect of time step discretization, initialization of stage profile, conservation of mass, iteration convergence, effectiveness evaluation, and convergence with different initial values are investigated.

\section{Effect of Time Step Discretization}

The different time steps, including 60, 40, 30, 20, 15, and $10 \mathrm{~min}$, for the dynamic routing model are used to investigate the effects of time step discretization on the predicted stage. The results of predicted stage at the Taipei Bridge during the Xangsane Typhoon (at peak time $t=15 \mathrm{~h}$ ) are listed in Table 2. The experimental results show that the effects of time steps from 10 to $60 \mathrm{~min}$ on predicted water stage are negligible. Because the four-point implicit finite-difference used in discretizing the dynamic wave equations is an unconditional stable scheme (Amein and Fang 1970), $1 \mathrm{~h}$ of time step discretization is used in the study.

\section{Initialization of Stage Profile}

The stage profiles are used to examine the reliability of the initialization of stage profile for flood forecasting. The spatial variation of the maximum stage $(t=15 \mathrm{~h})$ along the Tanshui River-Tahan Creek is computed for the Xangsane Typhoon event (shown in Fig. 5). Fig. 5 shows that the stage profiles calculated with roughness updating technique is about the same as that calculated with real time stage correction (Hsu et al. 2003), and they agree better with the observed data than the values calculated with the fixed Manning $n$. The results illustrate that the dynamic routing model with roughness updating technique can provide the reliability of the initialization of stage profile that improves the accuracy of subsequent forecast.

\section{Conservation of Mass}

The channel routing based on deterministic consideration, the error are introduced by the boundary condition (upstream, downstream, and lateral in flows) and by the roughness (Shiiba et al. 2000). The roughness affects the stage and storage in the river segment. To evaluate the conservation of mass in a river segment for the roughness updating technique, the relative error $\left(R_{e}\right)$ (the ratio of the nonconservative discharge including the net outflow and the rate of change in storage to the inflow discharge) is adopted (Hsu et al. 2003). The zero values of $R_{e}$ represent the mass conversation at a river segment. The computed relative errors for the Xangsane Typhoon are $5.43 \times 10^{-4}, 3.96 \times 10^{-4}$, $2.99 \times 10^{-4}$, and $4.97 \times 10^{-4}$, respectively, for the Tahan Creek, Hsintien Creek, Rukou-Shizitou, and Shizitou-river mouth. The results reveal that the nonconservative discharge introduced from the roughness updating technique and numerical method is negligible and almost maintains the conservation of mass. Computed errors are mainly introduced by freshwater discharges at the upstream boundaries, the numerical routing method, and roughness. From the analyses of mass conservation, the results reveal that the numerical routing method with roughness updating provides a small part of error when compared to the freshwater discharges from upstream boundaries. The freshwater discharge is calculated from hydrological model (Wang and Hsieh 2000) that has calibrated and verified with field data.

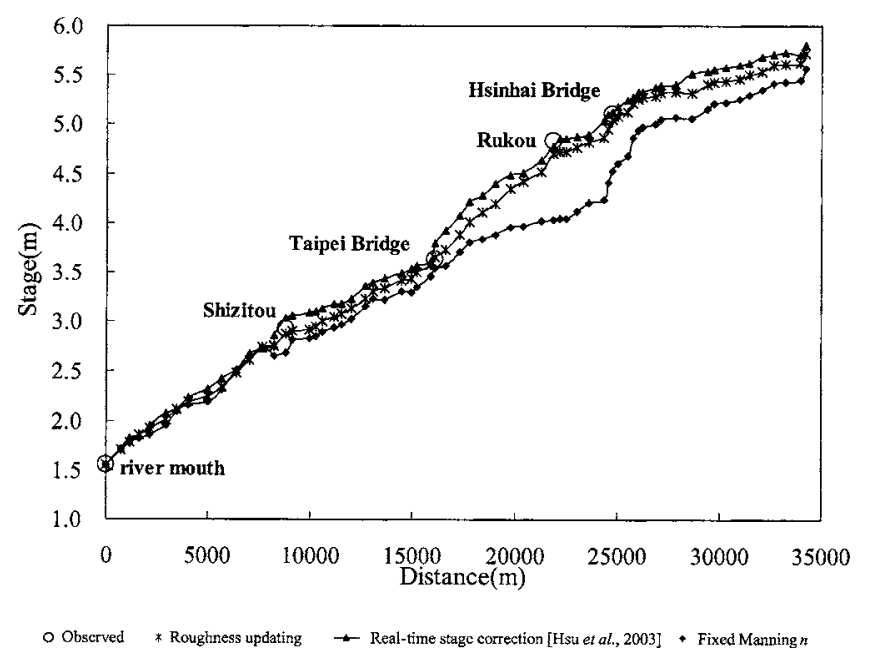

Fig. 5. The maximum stage profiles during the Xangsane Typhoon event in the Tanshui River-Tahan Creek 


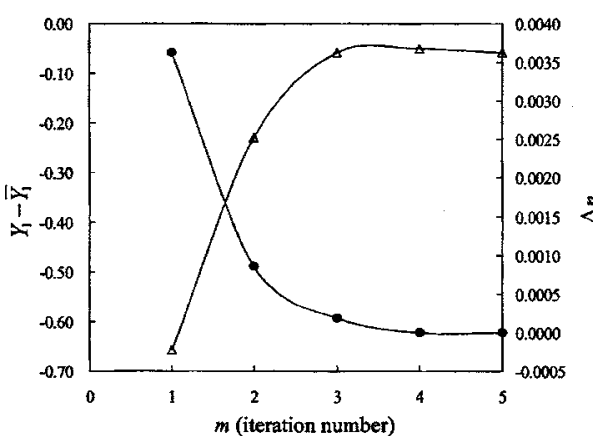

(a) Hsinhai Bridge

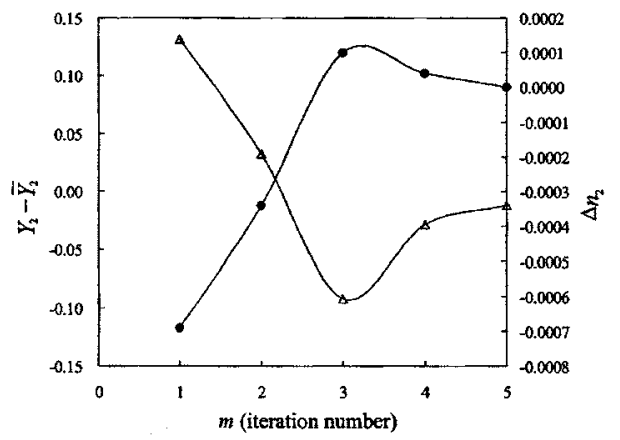

(b) Chungcheng Bridge

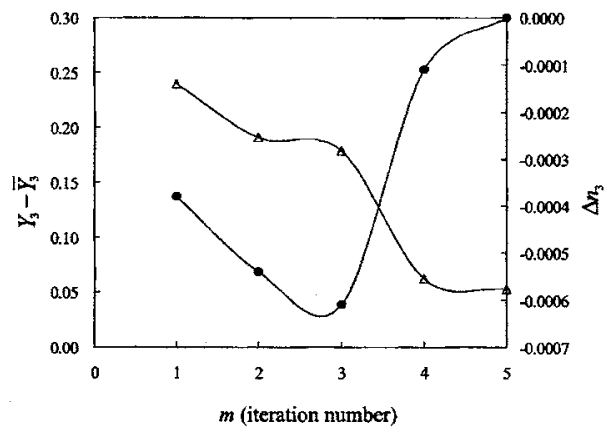

(c) Rukou

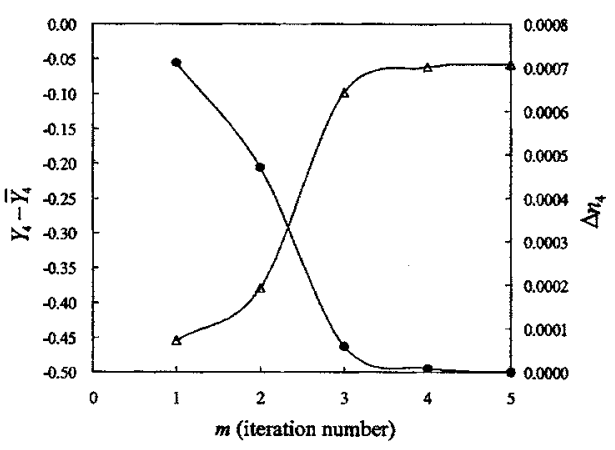

(d) Taipei Bridge

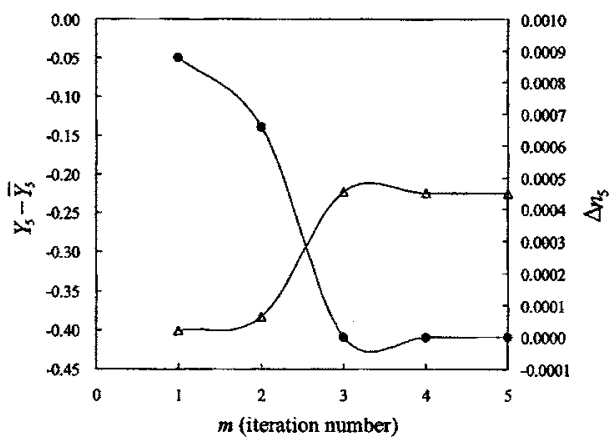

(e) Shizitou

$\triangle$ Difference of water depths

- Current increment of Manning $n$

Fig. 6. Iteration convergence through updating the Manning $n$

\section{Iteration Convergence}

The iteration convergence is used to examine the updating roughness increment between the $(m+1)$ and $m$ iteration levels in the Eq. (9). The Xangsane Typhoon event at the $t=15 \mathrm{~h}$ is used as the example to evaluate the results of iteration convergence for the current increment of Manning $n$. The computational results are presented in Fig. 6. In Fig. 6(a), the negative $\left(Y_{1}-\bar{Y}_{1}\right)$ indicates that computed water depth is lower than observed depth at Hsinhai Bridge. The roughness updating technique offers a positive quantity of the current increment of Manning $n\left(\Delta n_{1}\right)$ to elevate the computed water depth which is closer to the observed during the iteration processes. The similar results appear in Figs. 6(d and e) at Taipei Bridge and Shizitou, respectively. On the other hand, a negative quantity of $\Delta n_{3}$ can be found by using the roughness updating technique when $\left(Y_{3}-\bar{Y}_{3}\right)$ is positive at Rukon as shown in Fig. 6(c). Fig. 6(b) shows that the roughness updating technique has the availability of self-improvement at the Chungcheng Bridge. The results show that the difference of water depths at the third iteration increases by the excessively corrected values of Manning $n$ at second iteration. The third current increment is a positive value in Manning $n$ to decrease the difference of water depths. The roughness updating technique can reduce the difference of water depths in the fourth iteration. Fig. 5 shows that the current updating of Manning $n$ can be converged through several iterations. At the same time, the error of water depth $\left(Y_{k}-\bar{Y}_{k}\right)$ can be reduced gradually and fit the observed stage hydrograph. The roughness updating technique can eliminate the difference between the computed and observed water stages when the current increment of Manning $n\left(\Delta n_{k}\right)$ reaches the desired convergent criteria. Besides, the roughness updating technique will not function when the relative updating roughness increment $\left(\Delta n_{k} / n_{k}\right)$ is out of bounds that the stage information transmitted from gauge stations may be incorrect. In this study, the bounds of $\left(\Delta n_{k} / n_{k}\right)$ are set to \pm 0.5 .

\section{Effectiveness Evaluation}

The water stages at the present time computed by the dynamic routing model using the Manning $n$ at the previous time step (old Manning $n$ ) and the Manning $n$ at the present time step (newly updated Manning $n$ ) are called the computed stages before and after $n$ updating, respectively. They are used to compare the com- 


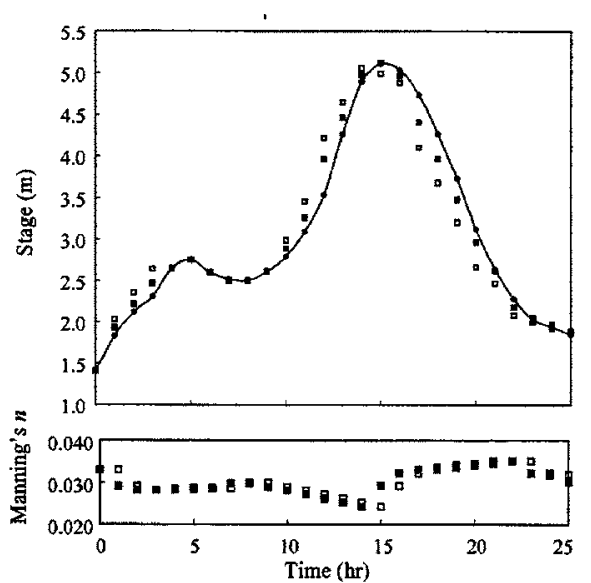

(a) Hsinhai Bridge

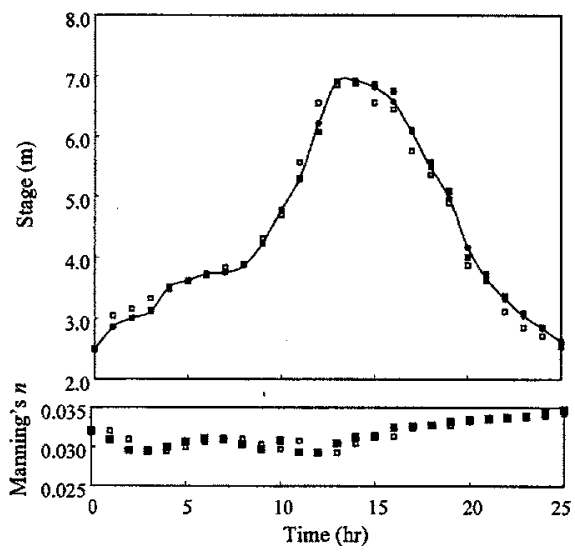

(b) Chungcheng Bridge

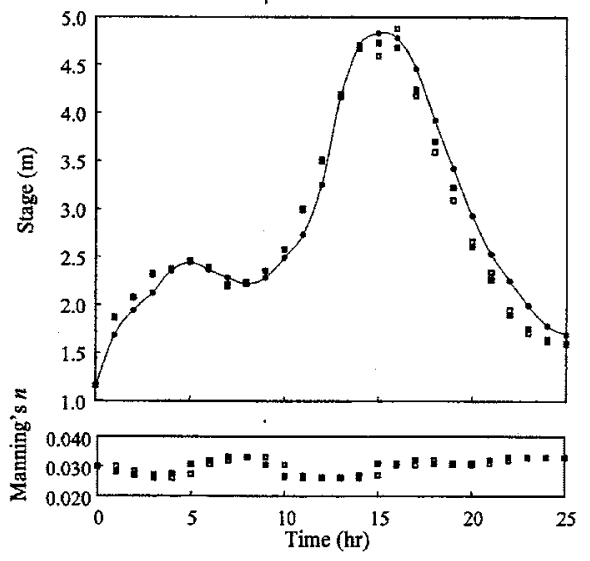

(c) Rukou

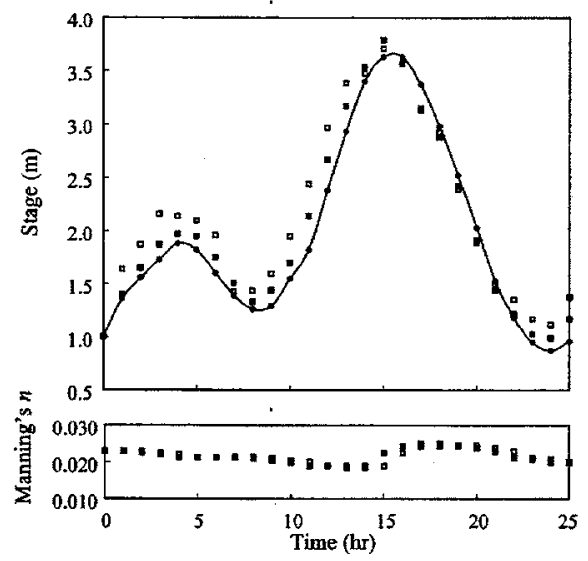

(d) Taipei Bridge

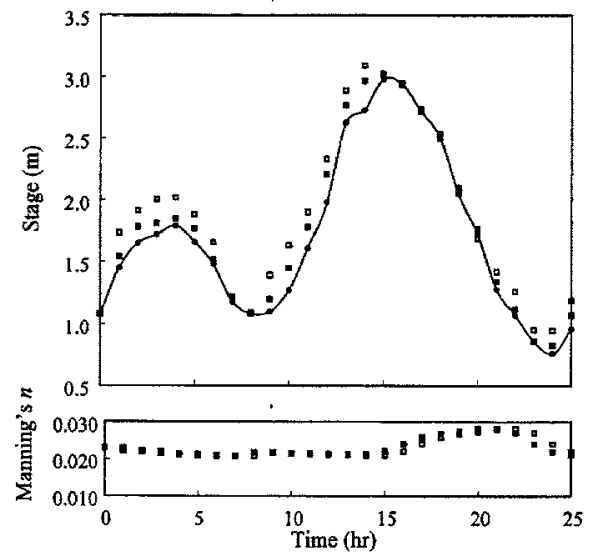

(e) Shizitou

Observed

- After $n$-updating

․ Before $n$-updating

Fig. 7. Computed stage hydrographs before/after $n$ updating during Xangsane Typhoon event

putational effectiveness of the roughness updating in each time as observation is received. Fig. 7 presents a comparison between observed stages and computed stages before/after $n$ updating during the Xangsane Typhoon event. If the Manning $n$ at the previous time step is used again at the present time in the dynamic routing model, the computed stages before $n$ updating are lower than the observed stage. The computed stages after $n$ updating can be elevated to match the observed values due to the roughness increment. On the other hand, a decrease in roughness makes a lower stage when the stage calculated by using the previous Manning $n$ is higher than the observed stage. Fig. 7 also shows that the dynamic routing model with roughness updating technique can significantly improve the computed water stage hydrograph to match the observed water stage hydrograph. The comparison of computed and observed stage at the peak time $(t=15 \mathrm{~h})$ is listed in Table 3. The results can be found that the computed stage before $n$ updating at the Hsinhai Bridge is $4.99 \mathrm{~m}$ which is lower than the observed value of $5.10 \mathrm{~m}$. Following the roughness updating processes, the Manning $n$ is updated automatically from 0.0282 to 0.0292 in the first river segment. The computed stage is then updated to $5.12 \mathrm{~m}$, which is closer to the observed value $(5.10 \mathrm{~m})$. The computational effectiveness shown in Table 1 illustrates that the technique can reduce computational errors of stage at each gauge station. The result revealed that roughness values are effectively lowered in the reach immediately downstream of 
Table 3. Comparison of the Observed and Computed Stages before/after $n$ Updating

\begin{tabular}{|c|c|c|c|}
\hline \multirow[b]{2}{*}{ Station } & \multirow{2}{*}{$\begin{array}{l}\text { Observed } \\
\text { stage } \\
(\mathrm{m})\end{array}$} & Before $n$ updating & After $n$ updating \\
\hline & & $\begin{array}{l}\text { Computed stage } \\
\text { (m)/Manning } n\end{array}$ & $\begin{array}{l}\text { Computed stage } \\
\text { (m)/Manning } n\end{array}$ \\
\hline Hsinhai Bridge & 5.10 & $4.99 / 0.0282$ & $5.12 / 0.0292$ \\
\hline Chungcheng Bridge & 6.81 & $6.66 / 0.0323$ & $6.86 / 0.0335$ \\
\hline Rukou & 4.83 & $4.92 / 0.0280$ & $4.78 / 0.0270$ \\
\hline Taipei Bridge & 3.63 & $3.87 / 0.0119$ & $3.79 / 0.0224$ \\
\hline Shizitou & 2.98 & $3.08 / 0.0221$ & $3.03 / 0.0210$ \\
\hline
\end{tabular}

the gauging station if calculated levels are too high, whereas these are raised when calculated levels are too low in the $n$-updating processes.

\section{Convergence Test with Different Initial Values}

A conventional trial-and-error calibration methodology to determine the Manning $n$ is usually time consuming. This work demonstrates that the roughness updating technique can provide an automatic and quick procedure for parameter determination. Several initial Manning $n$ in reasonable range for all river segments are selected for tests with the Xangsane Typhoon event. The initial values include $0.050,0.040,0.035,0.030$, and 0.025 of the Manning $n$ for all river segments. The computational results are presented in Fig. 8. The analytical results reveal that all tested initial values of the Manning $n$ converge to the same value within several iterations. Fig. 8(a) indicates that the various initial Manning $n$ at the Hsinhai Bridge-Rukou are automatically updated from $0.050,0.040,0.035,0.030$, or 0.025 to a proper $n$ value of 0.0188 after six iterations. The other river segments also display the same characteristics and update the Manning $n$ to 0.0354 , $0.0271,0.0253$, and 0.0195 as shown in Fig. 8, respectively. The convergence test with different initial values shows that the roughness updating technique provides a capable tool to search for the suitable Manning $n$ for the natural river.

The CPU time for the fixed Manning $n$ and real time roughness updating for $1-6 \mathrm{~h}$ forecasting in the Tanshui River are 1.26 and $1.73 \mathrm{~s}$, respectively, with a Pentium IV $2.8 \mathrm{G}$ computer.

\section{Analysis of Flood Forecast}

As described in the previous section, the rationality and capability of the roughness updating technique in the dynamic routing model have been verified. Three typhoon events, Bilis (2000), Prapiroo (2000), and Nari (2001), are then used to validate reliability of the roughness updating technique for stage forecasting. In the three typhoon events, the upstream and downstream boundary conditions are specified as the discharge and tidal stage, respectively. The input of the forecasting model includes the present time, observed and lead times forecasting data. The present time observed data are determined from the real time observed runoff at the five upstream boundaries and tidal stage at the river mouth. The $6 \mathrm{~h}$ lead time forecast data at the upstream and downstream boundaries were obtained from the rainfall-runoff and tidal stage forecasting models, which were developed by Wang and Hsieh (2000) and Hsu et al. (2000). The model is run to perform the stage forecasting using a roughness updating technique and the fixed Manning $n$ for $1-6 \mathrm{~h}$ ahead.

Fig. 9 presents the computed stage hydrograph at the Taipei Bridge for $6 \mathrm{~h}$ ahead during the three typhoon events. The result shows that the model results of the stage forecasting hydrograph with fixed Manning $n$ are far from the observed stage hydrograph and yield an uncertain prediction. But the stage forecasting hydrograph with a roughness updating technique is close to the observed stage hydrograph and yields a better prediction. The model has a good correcting capability with roughness updating technique to minimize the error of the forecasting values at $1-6 \mathrm{~h}$ ahead. Fig. 9 also shows that the dynamic routing with roughness updating technique has better prediction for the peak stage and time lag of the peak stage. The time-varying and fixed Manning $n$ at the Taipei Bridge-Shizitou for Typhoon Bilis, Prapiroo, and Nari used in this study are presented in Fig. 10. The experimental result shows that the range of time-varying Manning $n$ is around the fixed Manning $n$ for Typhoon Prapiroo, so that the fixed Manning's $n$ technique works well. The fixed Manning $n$ is suitable for Typhoon Prapiroo, but not for Typhoon Bills and Nari. The fixed Manning $n$ is far away from the time-varying Manning $n$ for Typhoon Bills and Nari. The reasons may result from the characteristics of typhoon events. Thus the computed stage with roughness updating technique to adjust the Manning $n$ matches the observed stage in the flood routing model according to the characteristics of typhoon events.

The coefficient of determination $\left(R^{2}\right)$ and root-mean-square errors (RMSE) between observed and forecasted stages are computed to evaluate the model performance. The RMSE can be written as

$$
\operatorname{RMSE}=\left\{\frac{1}{N}\left[\sum_{k=1}^{N}\left(Y_{k}-\bar{Y}_{k}\right)^{2}\right]\right\}^{1 / 2}
$$

where $N=$ total number of observed water depth at the $k$ th gauge station.

The forecasted and observed stages, for real time, 1,3 , and $6 \mathrm{~h}$ ahead at Taipei Bridge is presented in Fig. 11. If the forecasted and observed stages are equal, the data points will be on the solid, diagonal line of $45^{\circ}$. The value of $R^{2}$ is also specified in the figure. The better the accuracy of stage forecasting, the closer to 1.0 the value of $R^{2}$ is. The $R^{2}$ with the fixed Manning $n$ for the real time, 1,3 , and $6 \mathrm{~h}$ ahead are $0.883,0.885,0.854$, and 0.775 , respectively. Using roughness updating technique, the values of $R^{2}$ are 0.998, 0.979, 0.961, and 0.939, respectively. Comparison of these two results indicates that the stage forecasting using the roughness updating technique at $1-6 \mathrm{~h}$ ahead exhibits good performance.

Fig. 12 exhibits the RMSE for $1-6$ h predictions. The RMSE values of stage increase with the forecasting lead time for the fixed Manning $n$. They are $0.588,0.662$, and $0.718 \mathrm{~m}$ for the 1,3 , and $6 \mathrm{~h}$ lead-time predictions, respectively. The average RMSE is approximately $0.662 \mathrm{~m}$. The results indicate that the fixed Manning $n$ fails to respond to the resistance of river flow and provide inaccurate prediction. The RMSE of water stage calculated by the least-square method of stage correction (Hsu et al. 2003) were increased with lead time, such as, the 1, 3, and $6 \mathrm{~h}$ ahead are 


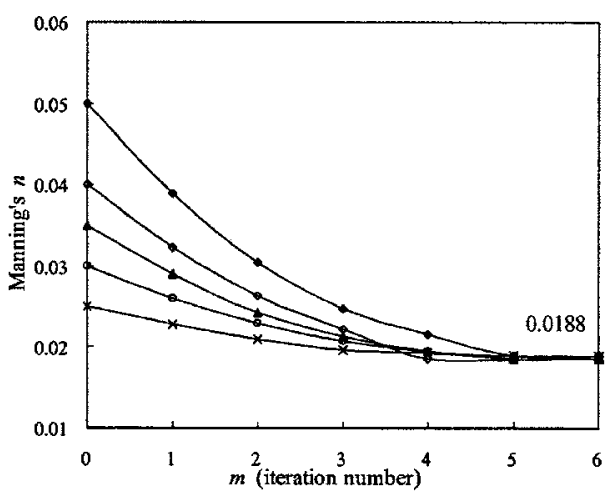

(a) first segment (Hsinhai Bridge-Rukou)

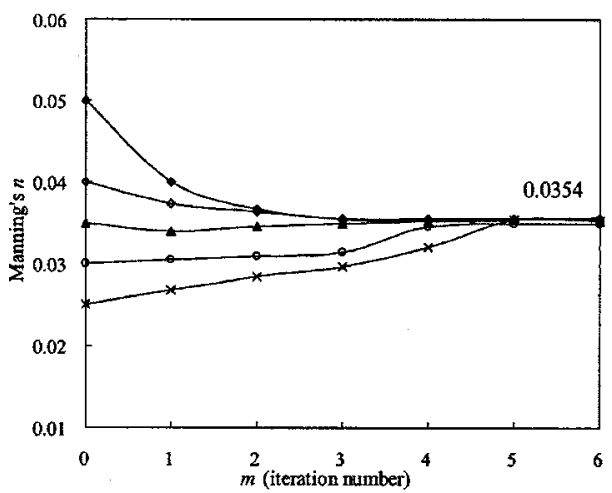

(b) second segment (Chungcheng Bridge-Rukou)

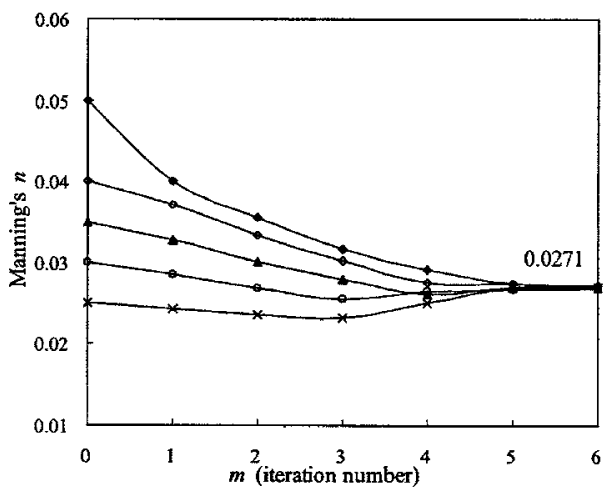

(c) third segment (Rukou-Taipei Bridge)

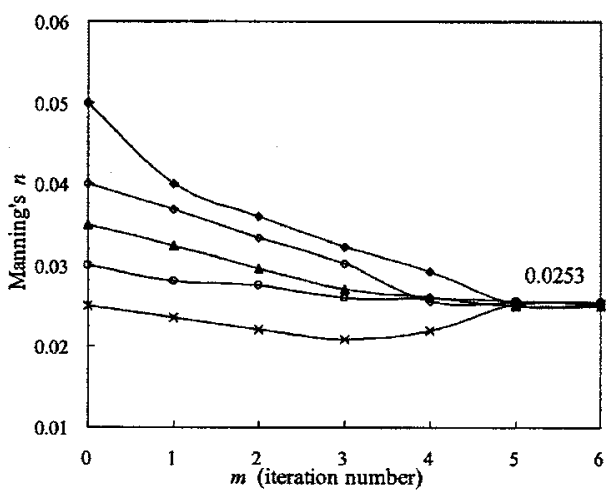

(d) fourth segment (Taipei Bridge-Shizitou)

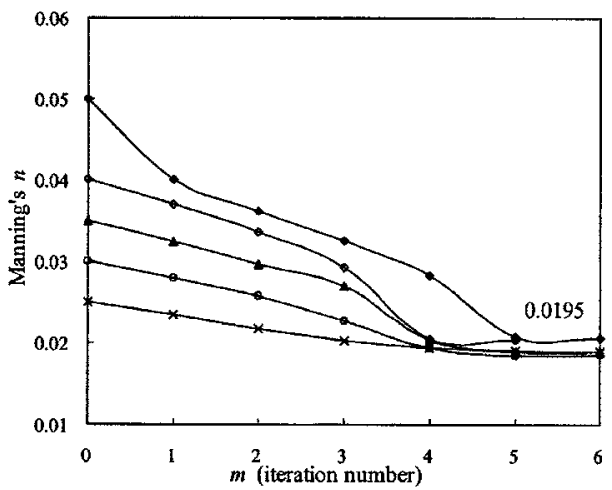

(e) fifth segment (Shizitou-River mouth)

$$
\begin{aligned}
& \text { Initial Manning } n \\
& \bullet n=0.050 \\
& \diamond n=0.040 \\
& \leftarrow n=0.035 \\
& \multimap n=0.030 \\
& * n=0.025
\end{aligned}
$$

Fig. 8. Convergence test with different initial Manning $n$

$0.207,0.405$, and $0.676 \mathrm{~m}$, respectively. The result shows that the improvement with real time stage correction method gradually diminished when one predicts far ahead in time. With the roughness updating in this study, the RMSE values for the 1,3 , and $6 \mathrm{~h}$ lead time predictions are $0.201,0.259$, and $0.308 \mathrm{~m}$, respectively. The average RMSE is approximately $0.262 \mathrm{~m}$. The study found that the roughness updating technique can promote a flood forecasting model in accuracy. The results indicate that the roughness updating technique can be an effective tool to minimize the error of the stage forecasting.

\section{Conclusions}

With the availability of the real time observed water depths at gauge stations in the Tanshui River, the roughness updating tech- nique of the dynamic routing model has been presented using the Gauss-Newton method to minimize the error of the stage forecasting. Moreover, the Jacobian of the residuals is expanded by the Manning formula and the nonuniform flow equation to produce an automatic updating technique for the Manning roughness coefficient. The Xangsane Typhoon event is selected to examine the initialization of stage profile, conservation of mass, iteration convergence, effectiveness evaluation, and convergence with different initial values by using the roughness updating technique. The results reveal that the dynamic routing model with roughness updating technique improves predictive capability.

Three typhoon events are used for the analysis of flood forecasting. The model is run to perform the stage forecasting using the roughness updating technique and the fixed Manning $n$ for $1-6 \mathrm{~h}$ lead time. The results demonstrate that the roughness updating technique is suitable for modeling the stages. However the 

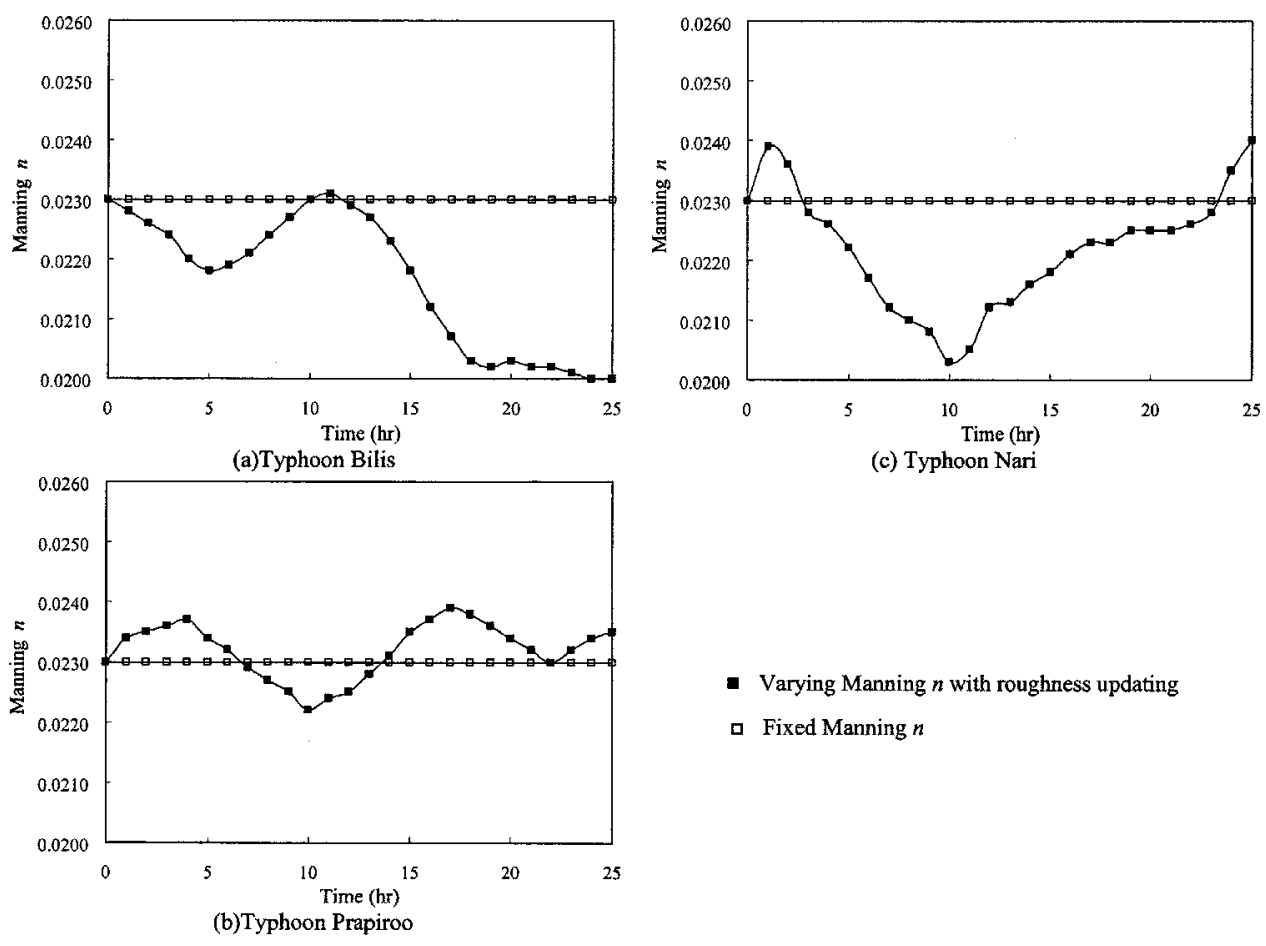

(c) Typhoon Nari

Fig. 9. Six hour stage forecasting of three typhoon events at the Taipei Bridge

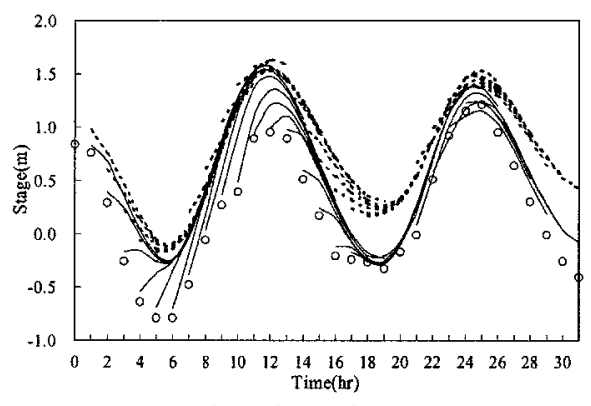

(a) Typhoon Bilis

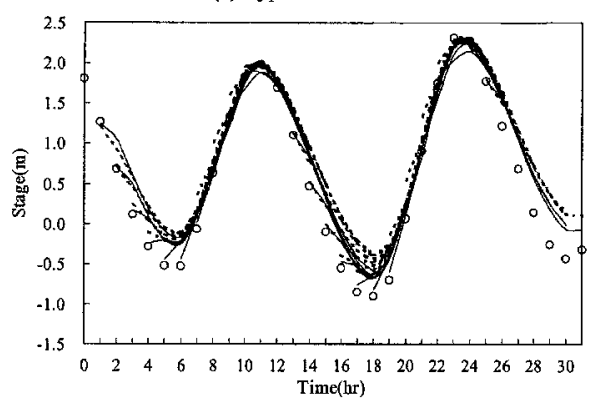

(b) Typhoon Prapiroo

- Observed

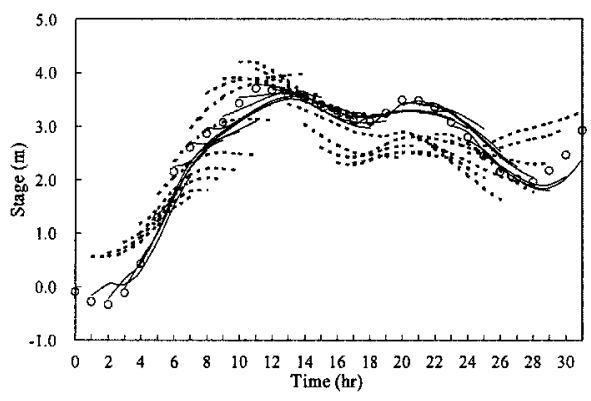

(c) Typhoon Nari
- Varying Manning $n$ with roughness updating

口 Fixed Manning $n$

Fig. 10. The time-varying and fixed Manning $n$ at the Taipei Bridge-Shizitou for three typhoon events 

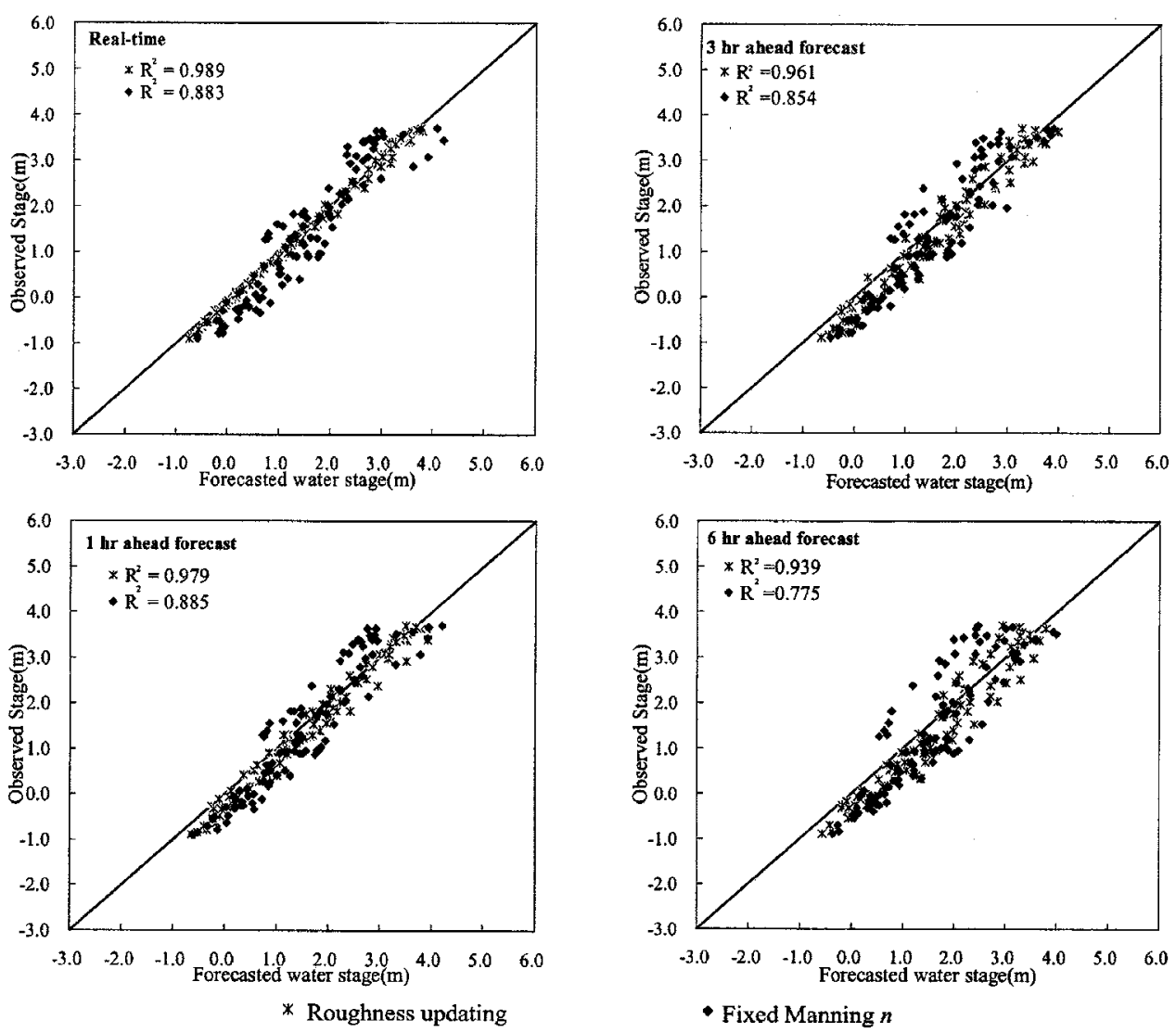

Fig. 11. The forecasted and observed stages at the Taipei Bridge for three typhoon events

model can improve the accuracy of stage hydrograph, stage profile, peak time, and satisfactory forecast stages from a lead time up to $6 \mathrm{~h}$. Therefore the new approach by combining the dynamic routing model with real time roughness updating technique can provide a useful tool for flood forecasting.

\section{Acknowledgments}

The authors express their grateful appreciation for the sponsorship of the National Science Council of Taiwan under Grant No. NSC-92-2625-Z-002-016. The measured data were provided by the Taiwan Water Resources Agency. The authors are also thankful to Dr. Albert Y. Kuo and three anonymous reviewers for their helpful reviews; through their comments and suggestions this paper was substantially improved.

\section{Appendix}

Assuming that there is no lateral inflow to and outflow from the channel, the general differential equation of gradually varied flows in open channels can be derived as

$$
\frac{d Y}{d x}=\frac{S_{0}-S_{f}}{1-\mathrm{F}^{2}}
$$

where $\mathrm{F}=$ Froude number.

Eq. (21) can be discretized between the two cross sections of the gauge stations $i$ and $(i+1)$ by finite difference method

$$
Y_{i}=Y_{i+1}-\psi_{i}
$$

$$
\psi_{i}=\left(\frac{S_{0}-\frac{1}{2}\left(S_{f i}+S_{f i+1}\right)}{1-\frac{1}{2}\left(F_{i}^{2}+F_{i+1}^{2}\right)} \Delta X_{i}\right)
$$

where $\psi_{i}=$ difference form of water depth between the two adjoining gauge stations by the finite difference method, and the

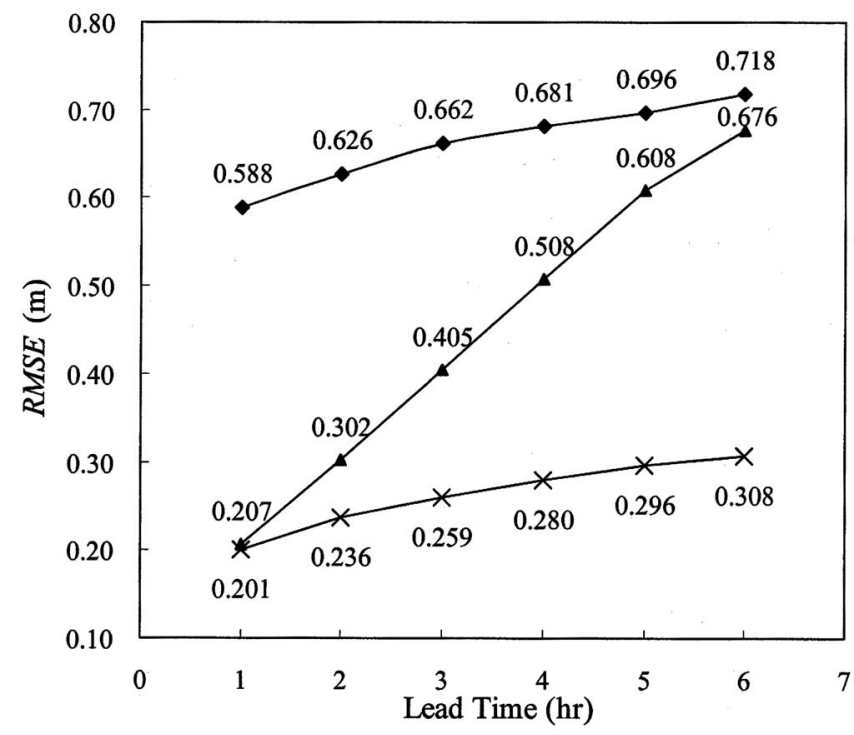

Fig. 12. Model evaluation results for different lead time forecasts 
subscript $i$ is the gauge station index with numbering from upstream to downstream, $\Delta X_{i}=X_{i+1}-X_{i}$.

For $j>i$, the derivative of Eq. (22) with respect to the Manning roughness $n_{j}$ can be found by using the chain rule

$$
\begin{aligned}
\frac{\partial Y_{i}}{\partial n_{j}}=\frac{\partial}{\partial n_{j}}\left(Y_{i+1}-\psi_{i}\right) & =\frac{\partial Y_{i+1}}{\partial n_{j}}-\left(\frac{\partial Y_{i+1}}{\partial n_{j}} \frac{\partial \psi_{i}}{\partial Y_{i+1}}+\frac{\partial Y_{i}}{\partial n_{j}} \frac{\partial \psi_{i}}{\partial Y_{i}}\right) \\
& =\frac{\partial Y_{i+1}}{\partial n_{j}}\left(1-\frac{\partial \psi_{i}}{\partial Y_{i+1}}\right)-\frac{\partial Y_{i}}{\partial n_{j}} \frac{\partial \psi_{i}}{\partial Y_{i}}
\end{aligned}
$$

The relationship between the derivatives of $\partial \psi_{i} / \partial Y_{i+1}$ and $\partial \psi_{i} / \partial Y_{i}$ in Eq. (24) can be written as

$$
\frac{\partial Y_{i}}{\partial n_{j}}=\frac{\partial Y_{i+1}}{\partial n_{j}} D_{i}
$$

and

$$
D_{i}=\left(\frac{1-\frac{\partial \psi_{i}}{\partial Y_{i+1}}}{1+\frac{\partial \psi_{i}}{\partial Y_{i}}}\right)
$$

In the similar way, the derivative term $\partial Y_{i+1} / \partial n_{j}$ can be expressed in terms of $\partial Y_{i+2} / \partial n_{j}$

$$
\frac{\partial Y_{i+1}}{\partial n_{j}} D_{i}=\left(\frac{\partial Y_{i+2}}{\partial n_{j}} D_{i+1}\right) D_{i}
$$

Following the processes, we can get

$$
\frac{\partial Y_{i}}{\partial n_{j}}=\left(\frac{\partial Y_{j}}{\partial n_{j}}\right) D_{j-1} D_{j-2} \cdots D_{i+1} D_{i}
$$

Substituting Eq. (14) into Eq. (28), we can get

$$
\frac{\partial Y_{i}}{\partial n_{j}}=\frac{3 Y_{j}^{j-1}}{5 n_{j}} \prod_{\lambda=i}^{j} D_{\lambda}
$$

where $\stackrel{i}{П} D_{\lambda}=D_{i} D_{i+1} D_{i+2} \cdots D_{j-1}$, and $\lambda=j-1$

$$
D_{\lambda}=\left(\frac{1-\frac{\partial \psi_{\lambda}}{\partial Y_{\lambda+1}}}{1+\frac{\partial \psi_{\lambda}}{\partial Y_{\lambda}}}\right)
$$

Neglecting the effects of higher order terms, the $\partial \psi_{\lambda} / \partial Y_{\lambda+1}$ and $\partial \psi_{\lambda} / \partial Y_{\lambda}$ in Eq. (30) may be written as

$$
\begin{aligned}
\frac{\partial \psi_{\lambda}}{\partial Y_{\lambda+1}} & =\frac{\left(1-\frac{1}{2}\left(F_{\lambda}^{2}+F_{\lambda+1}^{2}\right)\right)\left(\frac{5}{3} \frac{S_{f \lambda+1}}{Y_{\lambda+1}}\right)-\left(S_{0}-\frac{1}{2}\left(S_{f \lambda}+S_{f \lambda+1}\right)\right)\left(\frac{3}{2} \frac{F_{\lambda+1}^{2}}{Y_{\lambda+1}}\right)}{\left(1-\frac{1}{2}\left(F_{\lambda}^{2}+F_{\lambda+1}^{2}\right)\right)^{2}} \Delta X_{\lambda} \\
\frac{\partial \psi_{\lambda}}{\partial Y_{\lambda}} & =\frac{\left(1-\frac{1}{2}\left(F_{\lambda}^{2}+F_{\lambda+1}^{2}\right)\right)\left(\frac{5}{3} \frac{S_{f \lambda}}{Y_{\lambda}}\right)-\left(S_{0}-\frac{1}{2}\left(S_{f \lambda}+S_{f \lambda+1}\right)\right)\left(\frac{3}{2} \frac{F_{\lambda}^{2}}{Y_{\lambda}}\right)}{\left(1-\frac{1}{2}\left(F_{\lambda}^{2}+F_{\lambda+1}^{2}\right)\right)^{2}} \Delta X_{\lambda}
\end{aligned}
$$

\section{Notation}

The following symbols are used in this paper:

$A=$ cross-sectional area;

$B=$ surface width;

$C_{\ell}=$ discretized continuity equation;

$D_{\lambda}, D_{1}^{\prime}, D_{2}, D_{3}, D_{4}$

$=$ coefficients due to backwater effects;

$E=$ difference of water depths;

$\mathrm{F}=$ Froude number;

$f=$ objective function;

$g=$ gravitational acceleration;

$K=$ total number of gauge station;

$k=$ gauge station index;

$L=$ total number of cross section;

$\ell=$ cross-sectional index;

$M_{\ell}=$ discretized momentum equation;

$m=$ iteration number;

$N=$ total number of observed water depth;

$n, n_{1}, n_{2}, n_{3}, n_{4}, n_{5}$

$=$ Manning's roughness coefficient;
$Q=$ discharge;

$q_{1}=$ lateral inflow per unit channel length;

$q_{2}=$ lateral outgoing overflow per unit channel length;

$R=$ hydraulic radius;

$R_{e}=$ relative error;

$R^{2}=$ coefficient of determination;

RMSE $=$ root-mean-square error;

$S_{f}=$ friction slope;

$S_{0}=$ channel bottom slope;

$T=$ matrix transpose;

$t=$ time;

$V_{1}=$ longitudinal velocity component of lateral inflow;

$x=$ distance along the channel;

$Y=$ water depth;

$Y_{1}, Y_{2}, Y_{3}, Y_{4}, Y_{5}$

$=$ computed water depth;

$\bar{Y}_{k}=$ observed water depth;

$[\Delta \Omega]=$ current increment $n$ values;

$[\Phi]_{m}=$ Jacobian matrix of the residuals; 


$$
\begin{aligned}
\psi_{i}= & \text { difference formed by the finite difference } \\
& \text { method; } \\
\Omega= & \text { updating vector of } n \text { values; and } \\
{[\Omega]=} & n \text { values matrix of river segments. }
\end{aligned}
$$

\section{References}

Ackers, P. (1992). "Hydraulic design of two-stage channels." Proc. Inst. Civ. Eng., Waters. Maritime Energ., 96, 247-257.

Alain, L. (1992). "Estimation of Manning-Strickler roughness coefficient in Saint-Venant equations." Channel flow resistance: Centennial of Manning's formula, Water Resources, Littleton, Colo., 436-450.

Amein, M., and Fang, C. S. (1970). "Implicit flood routing in natural channel." J. Hydraul. Div., Am. Soc. Civ. Eng., 96(12), 2481-2500.

Camacho, L. A., and Lees, M. J. (1999). "Multilinear discrete lag-cascade model for channel routing." J. Hydrol., 226, 30-47.

Dey, S. (2002). "Free overall in circular channels flat base: A method of open channel flow measurement." Flow Meas. Instrum., 13, 209-221.

Henderson, F. M. (1966). Open channel flow, Macmillan, New York.

Hsu, M. H., Fu, J. C., and Liu, W. C. (2003). "Flood routing with realtime stage correction method for flash flood forecasting in the Tanshui River, Taiwan." J. Hydrol., 283, 267-280.

Hsu, M. H., Lin, S. H., and Fu, J. C. (2000). "Flood forecast system model for Tanshui River basin. IV: Flood routing model." Hydroinformatics 2000 Conf., Univ. of Iowa, Iowa.

Jorge, N., and Stephen, J. W. (1999). Numerical optimization, Springer, New York.

Kachroo, R. K. (1992). "River flow forecasting. I: A discussion of the principles." J. Hydrol., 133, 1-15.

Khatibi, R. H., Williams, J. J. R., and Wormleaton, P. R., (2000). "Friction parameters for flows in nearly flat tidal channels." J. Hydraul. Eng., 126(10), 741-749.

Lamberti, P., and Pilati, S., (1996). "Flood propagation models for real- time forecasting." J. Hydrol., 175, 239-265.

Lee, T. H., Chang, J. L., Chiang, C. H., and Tsai, H. C. (2000). "Flood forecast system model for Tanshui River basin. I: Climatology typhoon quantitative precipitation forecast model." Hydroinformatics 2000 Conf., Univ. of Iowa, Iowa.

Liggett, J. A., and Chen, L. C. (1994). "Inverse transient analysis in pipe networks." J. Hydraul. Eng., 120(8), 934-955.

Liu, W. C., Hsu, M. H., and Wang, C. F. (2003). "Modeling of flow resistance in mangrove swamp at mouth of tidal Keelung River, Taiwan." J. Waterw., Port, Coastal, Ocean Eng., 129(2), 86-92.

Nguyen, Q. K., and Kawano, H., (1995). "Simultaneous solution for flood routing in channel networks." J. Hydraul. Eng., 121(10), 744-750.

Preissman, A., (1961). "Propagation of translatory waves in channels and rivers." Proc., 1st Congress of French Association for Computation, Grenoble, France, A. F. C. A. L., 433-442 (in French).

Randy, D. C., Chiu, C. L., and Yu, W. (1993). "Uncertainties in flow modeling and forecasting for Niagara River." J. Hydraul. Eng., 119(11), 1231-1249.

Romanowicz, R., and Beven, K. (2003). "Estimation of flood inundation probabilities as conditioned on event inundation maps." Water Resour. Res., 39(3), 1-12.

Saavedra, I., Lopez, J. L., and Garcia-Martinez, R., (2003). "Dynamic wave study of flow in tidal channel system of San Juan River." $J$. Hydraul. Eng., 129(7), 519-526.

Shiiba, M., Laurenson, X., and Tachikawa, Y., (2000). "Real-time stage and discharge estimation by a stochastic-dynamic flood routing model." Hydrolog. Process., 14, 481-495.

Wang, R. Y., and Hsieh, L. S. (2000). "Flood forecast system model for Tanshui River basin. II: Runoff forecast mode." Hydroinformatics 2000 Conf., Univ. of Iowa, Iowa.

Yen, C. L., Lee, T. H., Wang, R. Y., Yang, D. L., and Hsu, M. H. (1998). "Research and development of flood forecasting system model for Tanshui River Basin.” Technical Rep., Water Resources Agency of the Ministry of Economic Affairs, China (in Chinese). 